\title{
17 TIPS KUNCI \\ MANAJEMEN PENDIDIKAN \\ YANG HARUS DIKETAHUI
}

\section{Siti Umi Mufarrochah}

Universitas Nahdlatul Ulama Sidoarjo

Kiat untuk Kepala Sekolah atau pemilik sekolah atau wirausahawan pendidikan untuk manajemen pendidikan ini telah membuat banyak tim administrasi lebih sukses dan telah membantu mereka membangun kepemimpinan di sekolah mereka. Kami telah mengumpulkan beberapa tips untuk Kepala Sekolah berdasarkan ulasan tentang sifat-sifat kunci dan umum dari para pemimpin yang telah saya ajak bicara dan yang telah menyumbangkan ide.

Pendidikan itu sebuah perhiasan dalam kemakmuran dan tempat bernaung dalam kesengsaraan (Maula, Mufidah, Rosyidah, \& Purnomo, 2017). Guru merupakan seorang yag memilki tugas mulia sebagai pendidik dan pengajar sekaligus sebagai pembentuk kepribadian siswa (Maula et al., 2018). Cari ilmu yang bermanfaat dan patuhi aturan-aturan yang ada. Bijaksana dan pantang menyerah dalam belajar adalah kunci kesuksesan. Pendidikan adalah pelajaran yang harus kita pelajari setiap hari baik dari buku, lingkungan, teman, maupun 
keluarga agar kita tidak tertinggal (Qori'ah, Sholichah, Purnomo, \& Rosyidah, 2017). Hasil penelitian menunjukkan bahwa penerapan pembelajaran dapat meningkatkan prestasi siswa; dan tes menunjukkan bahwa prestasi belajar siswa kelas belajar lebih baik daripada siswa kelas konvensional (Iskandar, Rizal, Kurniasih, Sutiksno, \& Purnomo, 2018). Tidak diragukan lagi berikut ini beberapa tips untuk para pemimpin sekolah.

\section{Memberi Tauladan}

Guru merupakan seorang pendidik dan pengajar sekaligus sebagai pembentuk kepribadian siswa yang unggul, berwawasan dan baik (Maula et al., 2018). Sebagai kepala sekolah, Anda adalah pemimpin bangunan. Setiap orang di gedung memperhatikan bagaimana Anda menjalankan bisnis harian Anda. Bangun reputasi sebagai pekerja tersulit di gedung Anda. Anda harus selalu menjadi yang pertama datang dan yang terakhir pergi. Sangat penting bahwa orang lain tahu betapa Anda mencintai pekerjaan Anda. Tetap tersenyum di wajah Anda, pertahankan sikap positif, dan tangani kesulitan dengan ketabahan dan ketekunan. Selalu jaga profesionalisme. Menghormati semua orang dan merangkul perbedaan. Jadilah model untuk kualitas dasar seperti organisasi, efisiensi, dan komunikasi (Meador, 2019). 


\section{FOKUS}

Singkatan ini diciptakan oleh John Lee Dumas, "Ikuti Satu Kursus Hingga Sukses." Pemimpin sekolah yang efektif, FOCUS (Bauer, 2019). Siswa perlu memahami apa yang diketahui dan apa yang diminta untuk memiliki kemampuan menjawab (Suci et al., 2018).

\section{Jadilah manusia}

Menjalin hubungan yang peduli dan profesional dengan guru, siswa, orang tua dan anggota dewan. Dengarkan baik-baik apa yang mereka katakan kepada Anda. Selalu tunjukkan bahwa Anda tertarik dan cobalah untuk menemukan apakah ada masalah atau masalah mendasar yang dapat Anda atau tim Anda selesaikan. Tindakan segera yang diambil untuk menyelesaikan masalah selalu dianggap positif oleh komunitas sekolah (Driscoll, 2018).

\section{Pisahkan Essential vs Non-Essential.}

Buku terbaik yang saya baca pada tahun 2014 mengguncang dunia saya dengan gagasan Essentialism. Sama seperti FOKUS, tidak setiap tugas itu penting (Bauer, 2019).

\section{Langkah Nyata Menjadi Pemimpin Pendidikan}

(Peel District School Board, 2019) Anda akan mendapatkan hasil maksimal dari aktivitas yang menarik minat Anda. Tetapkan tujuan kepemimpinan untuk diri sendiri. Anda tidak harus melakukan semuanya sekaligus. Mulai dari yang 
kecil - mungkin Anda hanya bisa memasukkan satu atau dua proyek ke dalam jadwal Anda tahun ini. Ingat, semakin banyak pengalaman yang Anda miliki, semakin mudah untuk menjadi pemimpin yang efektif. Untuk membantu Anda memulai, berikut adalah beberapa proyek yang perlu dipertimbangkan:

- di sekolah Anda, cari peluang kepemimpinan di luar dewan siswa - bergabung dengan tim, klub, atau asosiasi

- jika Anda berada di tim olahraga, pertimbangkan untuk mengambil peran yang lebih besar atau membantu siswa-siswa kecil terlibat dalam olahraga

- jika Anda adalah anggota komunitas agama, biasanya ada peran untuk para pemimpin remaja

- pilih masalah yang Anda minati - lingkungan, tunawisma, pekerja siswa - kemudian mulailah mempelajari semua yang dapat Anda lakukan dengan membaca koran, pergi ke perpustakaan dan mengunjungi situs web

- terhubung dengan organisasi yang mendukung masalah yang Anda minati

- mengatur acara khusus untuk meningkatkan kesadaran akan masalah atau perayaan penting, mis. HIV / AIDS, Bulan Sejarah Hitam, Hari Perserikatan Bangsa-Bangsa, dll.

- cari tahu bagaimana Anda dapat membuat perbedaan - menulis surat kepada pejabat 
pemerintah, menggalang dana, berbagi apa yang Anda ketahui dengan orang lain

- pelajari tentang apa yang dilakukan oleh siswa muda lainnya untuk mendukung masalah ini di komunitas Anda, secara provinsi, nasional atau bahkan internasional

- cari tahu siapa yang juga mendukung masalah ini - seorang pemimpin komunitas, seseorang yang Anda kagumi, seorang selebriti, pejabat pemerintah

- bergabunglah dengan pemuda dan pemuda Kanada di seluruh dunia untuk merayakan Hari Layanan Pemuda Global.

- sukarela di badan masyarakat setempat atau bank makanan

- gunakan keahlian Anda untuk membantu orang lain - merancang situs web, mengatur tampilan informasi, mengadakan acara khusus.

\section{Bersikaplah tenang}

Pendidikan Indonesia membutuhkan peningkatan akses, mutu dan relevansi pendidikan untuk manfaat membangun bagi pendidikan Indonesia (Irawan et al., 2018). Orang tua yang marah membuat anak lebih marah, sama seperti pelatih yang marah membuat pemain mereka lebih marah. Pemimpin harus melakukan apa saja untuk memastikan bahwa guru dan siswa tidak membiarkan emosi negatif mengganggu kinerja mereka. Itu berarti mereka harus siap di depan umum dan pribadi bahkan 
ketika ada berita buruk untuk didengar atau keputusan sulit dibuat. "Dalam situasi (sulit), selalu tetap tenang dan percaya diri untuk mempertahankan moral dan kepercayaan diri dalam komunitas sekolah (Watanabe-Crockett, 2018).

\section{Semangat Wirausaha}

Menjaga hubungan baik dengan wali siswa melalui melaksanakan janji dan pelayanan yang baik adalah bagian dari promosi wirausaha (Asitah, Usmawati, Rosyidah, \& Purnomo, 2017). Toleransi, bekerja sama, bertanggungjawab, dan amanah adalah prinsip wirausaha pendidikan (Nahdiyah, Amrina, Purnomo, \& Rosyidah, 2017). Edupreneur atau educational entrepreneur berasal dari dua kata yaitu education bermakna pendidikan dan entrepreneur bermakna pengusaha atau wirausahawan. Ada juga yang menyamakan istilah edupreneur dengan istilah teacherpreneur (Purnomo, 2017).

\section{Manajemen Religius}

Pendidikan adalah kunci untuk membuka pintu emas kesuksesan. Wirausaha pendidikan dengan motivasi bisnis dengan Allah Ta'ala sebagai bentuk kenyamanan untuk ibadah. Tips mengelola institusi pendidikan adalah niat mendidik dan berjuang karena Allah ta'ala. Niscaya rintangan sebesar apapun akan terasa ringan dihadapan kita. Melihat anak mengenal Allah Ta'ala dan sukses akhlak dan pengetahuannya merupakan kebahagiaan 
pendidik (Yuniarti, Kautsari, Sholichah, Purnomo, \& Rosyidah, 2017). Prinsip pendidikan adalah sosial. Sebagai seorang guru, kita harus memiliki kepedulian sosial (Asitah et al., 2017). Guru harus bisa membangun generasi muda untuk masa depan. Hiduplah untuk mengamalkan ilmu (Sholichah, Istiqomah, Rosyidah, \& Purnomo, 2017). Hubungan pendidikan antara guru dan murid itu seperti aliran listrik dengan lampu. Bagaimana lampu itu bisa menyala kalau aliran listriknya juga mati ?. Bagaimana murid itu bisa berprestasi sedangkan guru sendiri tidak pernah berprestasi dan mendoakan (Fidiana, Istiana, Rosyidah, \& Purnomo, 2017). Setiap manusia hamba Tuhan yang memiliki ilmu selayaknya harus mengamalkan ilmu tersebut (Asitah et al., 2017).

\section{Tetapkan Prioritas}

Pemimpin sekolah dan wirausaha pendidikan seharusnya senantiasa menikmati proses karena tidak ada hal yang besar yang tidak dilakukan dari hal yang kecil. Semua butuh proses, karena kesuksesan tidak datang secara langsung tanpa berproses (Maula et al., 2017). Bahkan sebelum tahun ajaran dimulai, pastikan Anda menetapkan prioritas. Jika melakukan walkthrough penting bagi Anda, letakkan di bagian atas daftar Anda. Jika Anda ingin fokus pada pengamatan di kelas, jadikan itu nomor satu Anda. Cobalah pisahkan tugas Anda berdasarkan urgensi dan ketahui perbedaan antara tugas penting dan sesuatu yang bisa menunggu. 
Menilai jumlah upaya yang akan dilakukan setiap tugas juga akan membantu Anda memesan agenda. Menggunakan aplikasi seperti Basecamp atau Wunderlist untuk membuat daftar hal-hal yang harus dilakukan akan membuat Anda lebih baik dalam perjalanan ke pengaturan dan prioritas (Kerns, 2016).

\section{Berjalan di Aula}

Cara memimpin sekolah adalah senantiasa musyawarah serta sharing bersama para guru atau dengan siapapun dan tetap mendekat pada Allah SWT (Yuniarti et al., 2017). Biasakan menyentuh basis setiap pagi dan tertarik dengan kehidupan orang lain, bahkan jika itu hanya menyapa dan mengajukan satu pertanyaan sederhana (Drewitt, 2017).

\section{Dukungan}

Kesabaran dan komunikasi yang baik dengan masyarakat sekitar adalah kunci untuk dapat mengatasi masalah dan bisa bangkit dari keterpurukan manajemen pendidikan (Qori'ah et al., 2017). Pertimbangkan untuk meminta dukungan Pembina Kepemimpinan yang Anda kagumi dan percayai. Itu bisa menjadi kesepian di puncak! (Driscoll, 2018).

\section{Menetapkan peran kepemimpinan}

Tips kelola sekolah adalah senantiasa belajar dan bekerja keras. Bersabarlah dengan masalah, sesungguhnya didalam kesulitan ada kemudahan (Sholichah et al., 2017). Rancang rencana disiplin seluruh sekolah dengan 
pemimpin guru Anda dan putuskan siapa yang paling berpotensi untuk memimpin orang lain dalam model kepemimpinan terdistribusi. Semakin banyak pemimpin yang muncul yang dapat Anda ciptakan, semakin banyak pengaruh yang Anda miliki di seluruh sekolah (Drewitt, 2017).

13.Minimalkan gangguan dan interupsi, dan belajarlah mengatakan "tidak".

Manajemen sekolah dilakukan dengan menerapkan standar kualitas dalam rekrutmen pengajar yaitu kedekatannya dengan amaliyah (Munjidah, Zannah, Purnomo, \& Rosyidah, 2017). Struktur kantor Anda dan jadwal Anda untuk meminimalkan waktu dan gangguan yang terbuang. Bahan-bahan yang dibutuhkan harus diatur dan mudah diakses, dan pekerjaan dengan prioritas tinggi harus dijadwalkan pagi hari, sore hari, atau selama periode pintu pendek yang tertutup pada siang hari. Juga, kepala sekolah harus mengembangkan kemampuan untuk mengatakan "tidak." Para pemimpin terbaik tahu bagaimana menyelesaikan pekerjaan prioritas paling banyak dalam sehari, dan itu tidak bisa dilakukan jika Anda menerima setiap permintaan (Murray, 2018).

\section{Pelihara notebook dan perencana tugas.}

Gunakan sistem yang membuat bahan terorganisir dan meminimalkan kehilangannya. Pengodean warna dapat membantu organisasi. Siswa Anda harus diinvestasikan dalam sistem 
apa pun yang diputuskan, bahkan jika itu bukan metode yang Anda sukai. Jika tugas tidak dicatat, atau tidak membuatnya pulang dan kembali ke sekolah, nilai persisnya di mana gangguan itu terjadi dan letakkan intervensi yang menangani gangguan tersebut (Springer, 2019).

\section{Mendorong guru untuk menggunakan situs jejaring sosial.}

Ketika datang ke sekolah selalu ada banyak diskusi tentang bagaimana siswa menggunakan atau menyalahgunakan situs jejaring sosial seperti Facebook. Namun, situs jejaring sosial ini dapat sangat bermanfaat bagi para guru dan mereka dapat membantu meningkatkan kinerja sekolah juga. Dari situssitus web ini, para guru dapat memperoleh ideide yang tepat tentang bagaimana mereka dapat mengajar berbagai mata pelajaran dan buku di kelas yang mereka temukan sulit untuk dihadapi (Fedena, 2018).

\section{Memahami properti sekolah}

Pemimpin sekolah sebisanya tegas, toleran terhadap bawahannya dan mengayomi (Fidiana et al., 2017). Panduan ini berisi informasi tentang perencanaan, manajemen, dan sistem properti (Educational Leaders, 2019). 


\section{Standar Tinggi}

Kepala sekolah yang efektif menjunjung tinggi standar untuk siswa, guru, dan diri mereka sendiri. 8. Kepala sekolah yang efektif berani. 9. Kepala sekolah yang efektif mengadvokasi mereka yang membutuhkan dukungan. 10. Kepala sekolah yang efektif memastikan bahwa kampus sekolah adalah tempat yang aman dan ramah untuk semua (Harris, 2019). 


\section{REFERENSI}

Asitah, N., Usmawati, D. Z., Rosyidah, E., \&

Purnomo, A. (2017). MI Hasyim Asy'ari llmu Harus Terus Mengarus. In Wirausaha Pendidikan Indonesia (Jilid 2). Sidoarjo: UNUSIDA Press.

Bauer, D. (2019). 200 Tips for Effective School Leaders. Retrieved June 11, 2019, from https://www.betterleadersbetterschools.com/ 200-tips-effective-school-leaders/

Communicator. (2017). 4 Time Management Tips for Principals. National Association of Elementary School Principals, 40. Retrieved from https://www.naesp.org/communicatorjune-2017/4-time-management-tipsprincipals

Covey, S. (1996). First things first. New York:

Simon and Schuster.

Drewitt, P. (2017). 25 tips for School Principals.

Retrieved June 10, 2019, from

https://www.linkedin.com/pulse/25-tips-

school-principals-paul-drewitt

Driscoll, M. (2018). 16 Success Tips for New

21st Century Principals. Retrieved June 23, 2019, from

https://thinkstrategicforschools.com/16success-tips-new-21st-century-principals/

Edsys. (2016). 10 Awesome Tips to Manage School Discipline Issues. Retrieved June 27, 2019, from https://www.edsys.in/10awesome-tips-to-manage-school-disciplineissues/ 
Educational Leaders. (2019). Guides for managing your school. Retrieved June 28, 2019, from

http://www.educationalleaders.govt.nz/Mana ging-your-school/Guides-for-managing-yourschool

Fedena. (2018). Quality tips for better school management. Retrieved June 24, 2019, from

https://fedena.com/blog/2018/11/quality-tipsfor-better-school-management.html Fidiana, W., Istiana, Z., Rosyidah, E., \&

Purnomo, A. (2017). MINU Waru 2 Insan Berkilau Cahaya Manfaat. In Wirausaha Pendidikan Indonesia (Jilid 4). Sidoarjo: UNUSIDA Press.

Harris, S. (2019). 10 Survival Tips for New,

Struggling School Principals. Retrieved June 21, 2019, from

https://www.teachhub.com/10-survival-tips-

for-school-principals

Irawan, D. E., Purnomo, A., Sutiksno, D. U.,

Abraham, J., Alamsyah, A., Saputra, D. H.,

... Rosyidah, E. (2018). Kajian Pendidikan

Tinggi IDRI untuk DPR RI dan Ristek Dikti 2018. Bandung: ITB Press.

Iskandar, A., Rizal, M., Kurniasih, N., Sutiksno,

D. U., \& Purnomo, A. (2018). The Effects of

Multimedia Learning on Students

Achievement in Terms of Cognitive Test

Results. Journal of Physics: Conference

Series, 1114(1), 012019.

https://doi.org/10.1088/1742- 
$6596 / 1114 / 1 / 012019$

Kane, A. (2018). 5 Essential Tips for Managing High School Students. Retrieved June 23, 2019, from

https://theartofeducation.edu/2018/07/02/5essential-tips-for-managing-high-schoolstudents/

Kerns, K. (2016). 5 Time Management Tips for School Administrators. Retrieved June 26, 2019, from

http://help.thesubservice.com/blog/5-timemanagement-tips-for-school-administrators Maula, I., Asitah, N., Munjidah, A., Nahdiyah, K., Yuniarti, D., Sholichah, S. A., ... Qori'ah, S. (2018). Kontribusi Kreativitas Guru SD dalam Induksi Pembelajaran. https://doi.org/http://doi.org/10.17605/OSF.I O/BS795

Maula, I., Mufidah, F. I., Rosyidah, E., \& Purnomo, A. (2017). SD Antawirya Islamic Javanese School Mother is Culture. In Wirausaha Pendidikan Indonesia (Jilid 1). Sidoarjo: UNUSIDA Press.

Meador, D. (2019). 10 Things a Successful School Principal Does Differently. Retrieved June 25, 2019, from

https://www.thoughtco.com/things-asuccessful-school-principal-does-differently3194532

Munjidah, A., Zannah, I. P. N., Purnomo, A., \& Rosyidah, E. (2017). MI Thoriqussalam Berpegang Kepada Rosul. In Wirausaha Pendidikan Indonesia (Jilid 4). Sidoarjo: 
UNUSIDA Press.

Murray, J. (2018). Time Management Tips for School Leaders - Part I. Retrieved June 25, 2019, from

https://www.ccu.edu/blogs/cags/2018/01/tim e-management-tips-for-school-leaders-parti/

Nahdiyah, K., Amrina, S., Purnomo, A., \& Rosyidah, E. (2017). SD Taman Pendidikan Islam Porong Iman Kuat Bekal di Akhirat. In Wirausaha Pendidikan Indonesia (Jilid 2). Sidoarjo: UNUSIDA Press.

Okoli, A. (2017). 3 Little Changes that Would Make a Big Difference to your School Management. Retrieved June 29, 2019, from https://safsms.com/blog/3-changes-toimprove-school-management/

Peel District School Board. (2019). Becoming an Effective Youth Leader. Retrieved June 20, 2019, from

http://www.peelschools.org/students/student activitycouncil/tipsforbeingeffectiveschoollea der/Pages/default.aspx

Purnomo, A. (2017). Pengertian Edupreneur. https://doi.org/10.31227/osf.io/8fnu6

Qori'ah, S., Sholichah, S. A., Purnomo, A., \& Rosyidah, E. (2017). Progresif Bumi Sholawat dengan Kebenaran Semua Pasti Ada Jalan. In Wirausaha Pendidikan Indonesia (Jilid 3). Sidoarjo: UNUSIDA Press. 
Sholichah, S. A., Istiqomah, A., Rosyidah, E., \& Purnomo, A. (2017). MI Darun Najah Berfikir Berkarya Berdzikir. In Wirausaha Pendidikan Indonesia (Jilid 3). Sidoarjo:

UNUSIDA Press.

Springer. (2019). Tips for Managing

Organization. Retrieved June 29, 2019, from https://www.springer-ld.org/springerexperience/center/parent-programs/tipsorganization

Suci, S. H. A., Rosyidah, E., Asitah, N., Aini, N., Murni, A. W., Anam, F., ... Kuraesin, A. D. (2018). Learning from Picture and Picture Action Research : Enhancement of Counting Ability on Division of Numbers for Primary School Students. Journal of Physics:

Conference Series, 1114(1), 012044. https://doi.org/10.1088/17426596/1114/1/012044

Watanabe-Crockett, L. (2018). The 10 School Leadership Best Practices That Make a Difference. Retrieved June 20, 2019, from https://www.wabisabilearning.com/blog/10school-leadership-best-practices Yuniarti, D., Kautsari, M. F., Sholichah, F., Purnomo, A., \& Rosyidah, E. (2017). SMP SMA Al-Amin Ponpes Bahrul Hidayah Serahkan pada Allah Ta'ala. In Wirausaha Pendidikan Indonesia (Jilid 1). Sidoarjo: UNUSIDA Press. 